Original Research

\title{
Human cardiomyocyte-derived exosomes induce cardiac gene expressions in mesenchymal stromal cells within 3D hyaluronic acid hydrogels and in dose-dependent manner
}

\author{
Burak Derkus (iD) ${ }^{1}$
}

Received: 4 August 2020 / Accepted: 10 December 2020 / Published online: 19 January 2021

(c) The Author(s) 2021

\begin{abstract}
Accomplishing a reliable lineage-specific differentiation of stem cells is vital in tissue engineering applications, however, this need remained unmet. Extracellular nanovesicles (particularly exosomes) have previously been shown to have this potential owing to their rich biochemical content including proteins, nucleic acids and metabolites. In this work, the potential of human cardiomyocytes-derived exosomes to induce in vitro cardiac gene expressions in human mesenchymal stem cells (hMSCs) was evaluated. Cardiac exosomes (CExo) were integrated with hyaluronic acid (HA) hydrogel, which was functionalized with tyramine (HA-Tyr) to enable the development of 3D (three dimensional), robust and bioactive hybrid cell culture construct through oxidative coupling. In HA-Tyr/CExo 3D hybrid hydrogels, hMSCs exhibited good viability and proliferation behaviours. Real time quantitative polymerase chain reaction (RT-qPCR) results demonstrated that cells incubated within HA-Tyr/CExo expressed early cardiac progenitor cell markers (GATA4, Nkx2.5 and Tbx5), but not cTnT, which is expressed in the late stages of cardiac differentiation and development. The expressions of cardiac genes were remarkably increased with increasing CExo concentration, signifying a dose-dependent induction of hMSCs. This report, to some extent, explains the potential of tissue-specific exosomes to induce lineage-specific differentiation. However, the strategy requires further mechanistic explanations so that it can be utilized in translational medicine.
\end{abstract}

Supplementary information The online version of this article (https:// doi.org/10.1007/s10856-020-06474-7) contains supplementary material, which is available to authorized users.

Burak Derkus

burakderkus@gmail.com

1 Department of Chemistry, Faculty of Science, Ankara University, 06560 Ankara, Turkey 


\section{Graphical Abstract}
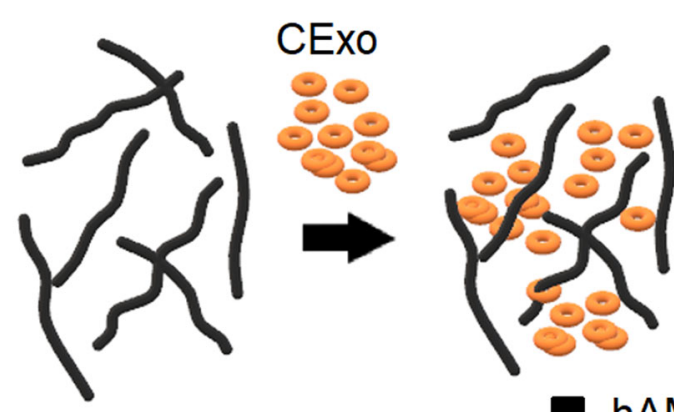

HA-Tyr
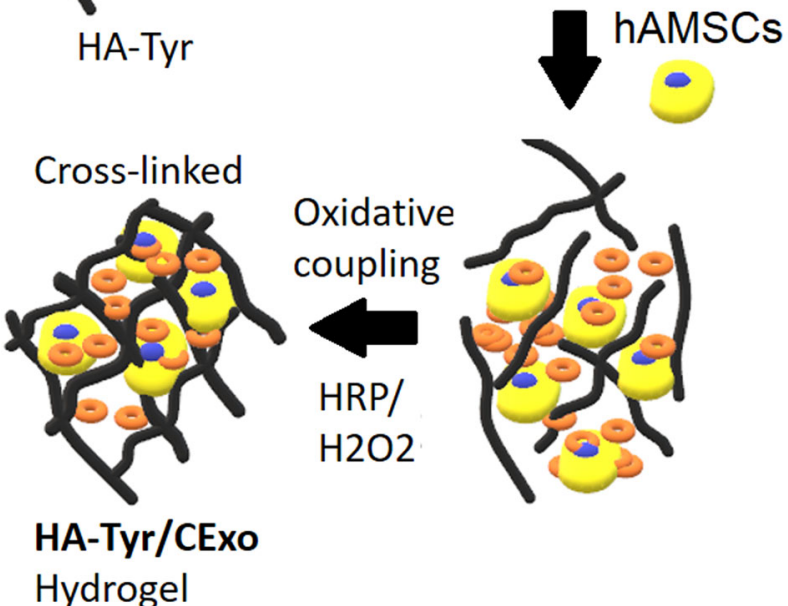

\section{Introduction}

Predicting and controlling lineage-specific differentiation of stem cells, particularly of multipotent and pluripotent cells, is one of the critical issues for tissue engineering and stem cell researches. Cardiogenic differentiation of stem cells is one of the processes in which we have limited knowledge compared with the other cell fates. Cardiogenic differentiation is a dynamic process involving nuclear translocation of NK2 homeobox $5(\mathrm{Nkx} 2.5)$ and GATA Binding Protein 4 (GATA4) [1], the cooperation of Homeobox A10 with Nkx2.5 to regulate the timing of differentiation [2], and the role of micro RNAs (miRNAs) that target different pathways [3].

Currently, different induction approaches to differentiate stem cells into cardiac lineages are being used. 5Aza-2'-deoxycytidine (5-AZA) is the most extensively used chemical inducer [4] and stimulates both multipotent [5] and pluripotent [6] cells into cardiomyocytes. However, it, induces cells via random demethylation of DNA [5], has carcinogenic potential, which limits in vivo applications [7], and is an exogenous inducer that may cause cell damage. Use of biological inducers including miRNAs [8-10], cytokines such as interleukin$1 \beta$, and growth factors namely transforming growth factor- $\beta[11,12]$, hepatocyte growth factor, insulin-like growth factor-1, and Islet1 $[13,14]$ is another strategy for differentiating the stem cells into cardiogenic lineage. Despite these progresses, cardiogenic differentiation remained inefficient $(<10 \%)$ [15]. Therefore, sophisticated approaches that will improve the yield of differentiation are needed, and it is believed that exosomes can be harnessed for the reliable induction of stem cells.

Exosomes are nano-sized $(50-150 \mathrm{~nm})$ vesicles, which tend to be secreted toward extracellular environments [16]. After their rich biological contents including RNAs, miRNAs, proteins, metabolites and roles in biological processes were discovered, exosomes have been used in many fields of biological and medical sciences including cell biology [16], regenerative medicine [17], drug delivery [18] as well as in diagnosis of diseases involving cancer [19], infectious diseases [20] and neurodegenerative diseases [21]. Exosomes also offer an opportunity for cell reprogramming and have been exploited in neurogenic [22], adipogenic [23], osteogenic [24], odontogenic [25] and myogenic [26] differentiation of stem cells. Particularly, exosomes derived from cardiac cells play vital roles in many biological processes. For instance, they modulate mammalian target of rapamycin signalling pathways and attenuate apoptosis [27], manage endogenous stem cell plasticity and tissue regeneration after damage [28] and regulate inflammatory processes [29]. Despite the biological potentials of cardiac exosomes (CExo), their potential in stem cell differentiation 
has not been explored in vitro. Recent work demonstrated that rat mesenchymal stem cells (rMSCs) could be transformed into cardiomyocytes by co-culturing with cardiomyocytes [30], and this finding reveals that paracrine mechanisms may play a significant role in cardiac transdifferentiation. Inspired by this previous work and those that utilize exosomes for cell reprogramming, the work reported herein seeks to harness the potential of exosomes for lineage-specific differentiation-cardiac trans-differentiation —of mesenchymal stem cells.

To demonstrate the possibility to use exosomes to induce lineage-specific differentiation, threedimensional (3D) hyaluronic acid (HA)-based hydrogels encapsulating human cardiomyocyte cells-derived exosomes were developed. HA was used to provide a biocompatible microenvironment, which was functionalized with Tyr (HA-Tyr) to control stability and mechanical properties through orthogonal enzymatic cross-linking reaction of Tyr that results in the formation of dityramine moiety, as previously described by Derkus et al. [31]. It brings various advantages in 3D cell culture, such as fast gelling time $(<1 \mathrm{~min})$, gradually degradation by hyaluronidase enzyme, and ease-ofmanipulation. Besides, HA is the largest glycosaminoglycan macromolecule in cardiac ECM [32] and involved in cardiac development [33]. All these features make HA-based hydrogels one of the most suitable materials for cardiac-cell-culture applications. The strategy proposed in this work opens opportunities for growth-factor-free induction of human mesenchymal stem cells (hMSCs) into cardiac cells and in vivo application for cardiac tissue regeneration thereof.

\section{Materials and methods}

\section{1 hMSCs and human cardiomyocytes cell culture}

The hMSCs (derived from healthy human adipose tissue) were supplied by Dr. Yavuz Emre Arslan's laboratory (Canakkale On Sekiz Mart University, Turkey). The MSCs were in spindle-shape fibroblastic morphology and expanded using a commercial low-serum hMSC growth medium (Cat No. 7501, ScienCell, USA). Passages 4-6 were used for the experiments. Human cardiomyocyte (HCM) cells isolated from the ventricles of healthy adult human heart (PromoCell, Germany) were cultured in high glucose Dulbecco's Modified Eagle's medium (Sigma-Aldrich Inc., USA) supplemented with 10\% exosome-depleted foetal bovine serum (System Biosciences, USA) and $1 \%$ penicillin/streptomycin (Thermo Fisher Scientific, USA). The cells were detached using Trypsinethylenediaminetetraacetic acid (Thermo Fisher Scientific, USA) when they reached confluency.

\subsection{Isolation and characterisation of CExo}

Exosomes were isolated from primary human cardiomyocyte cells via serial ultracentrifugation as previously described [19]. Briefly, conditioned medium (CM) was collected from primary human cardiomyocyte cells that were cultured at $37^{\circ} \mathrm{C}$ under $5 \% \mathrm{CO}_{2}$ conditions. $\mathrm{CM}$ was then centrifuged (Universal $320 \mathrm{R}$, Hettich, Germany) for $15 \mathrm{~min}$ at $300 \mathrm{~g}$ and $4{ }^{\circ} \mathrm{C}$ to remove the cells, filtered through $0.22-\mu \mathrm{m}$ filters, centrifuged again for $15 \mathrm{~min}$ at $10,000 \mathrm{~g}$ and $4{ }^{\circ} \mathrm{C}$ - to remove cell remnants, apoptotic bodies and microvesicles-and finally ultracentrifuged (Himac CP100WX, Hitachi, USA) for $70 \mathrm{~min}$ at $120,000 \mathrm{~g}$ and $4{ }^{\circ} \mathrm{C}$ to pellet the exosomes. The isolated exosomes were re-suspended in medium and characterized with a bicinchoninic acid (BCA) test kit (Thermo Fisher Scientific, USA), ELISA kit for CD63 (System Bioscience, USA) and transmission electron microscopy (TEM).

For the quantification of exosomal protein content, exosome lysates were obtained by adding an equal volume of the radioimmunoprecipitation assay buffer (Thermo Fisher Scientific, USA) including protease inhibitors. Protein standards were prepared using bovine serum albumin in concentrations between $5 \mu \mathrm{g} \mathrm{mL}^{-1}$ and $50 \mathrm{mg} \mathrm{mL}^{-1}$. Optic measurements of protein standards and exosome samples were recorded at $562 \mathrm{~nm}$ on a microplate reader (Thermo Scientific, Multiskan Sky Microplate Spectrophotometer) after incubation with $\mathrm{BCA}$ reagent at $37{ }^{\circ} \mathrm{C}$ for $30 \mathrm{~min}$. The level of $\mathrm{CD} 63+$ exosome particles was quantified with ExoELISA CD63 (System Biosciences) following the user instruction. TEM, additionally, was used to confirm the morphology of the individual exosomes and their specific diameter changing between 50 and $150 \mathrm{~nm}$. For this purpose, $10 \mu \mathrm{L}$ of sample was treated with $4 \%$ paraformaldehyde for fixation and $10 \mu \mathrm{L}$ of the fixed exosomes were deposited onto a piece of parafilm. TEM grid was laid down onto droplet, and allowed to adsorb exosomes for $10 \mathrm{~min}$. The grids were transferred onto a $1 \%$ glutaraldehyde droplet placed onto parafilm for further fixation. After counterstaining with $0.5 \%$ uranyl acetate for $2 \mathrm{~min}$, exosomes were observed under TEM (JEM 2100-F, USA).

\subsection{Development of CExo loaded HA-Tyr (HA-Tyr/CExo) 3D hybrid gels}

Stable 3D hydrogels comprising HA-Tyr (obtained from Creativepegworks, Cat No: HA-387, MW 2.500 k), CExo and hMSCs were formed by mixing CExo with HA-Tyr, inoculating the cells and triggering oxidative coupling reaction via interaction of hydrogen peroxide $\left(\mathrm{H}_{2} \mathrm{O}_{2}\right)$ and horse radish peroxidase (HRP) (Fig. S1). The gels to be tested in experimental setups were prepared in 96-well plates as follow: $50-\mu \mathrm{L}$ HA-Tyr - that contains HRP 
(3 U/mL) - in different concentrations (final conc. 1, 3 and $6 \%$ ) was placed in wells, and CExo in different concentrations $(10,50$ or $100 \mu \mathrm{g}$ in 5,10 and $20 \mu \mathrm{L}$ medium, respectively) were added thereafter. The gelation was triggered by injecting 5- $\mu \mathrm{L} \mathrm{H}_{2} \mathrm{O}_{2}$ (1-mM Stock, $0.0125 \mathrm{mM}$ final conc.) following cell inoculation in 5- $\mu \mathrm{L}$ medium. HATyr works through a very fast gelling mechanism, which is $<1 \mathrm{~min}$, so the gels could be washed for several times right after the cross-linking step, to prevented cell damage. This very fast gelling property makes HA-Tyr a suitable material for 3D cell culture.

\subsection{Microstructural and mechanical characterisations of HA-Tyr gels}

The micro-architecture and mechanical properties of HATyr gels in varying mechanical strength were examined by monitoring with scanning electron microscopy (SEM) as well as testing with the micro-mechanical tester. Gels were processed for SEM with freeze-dryer to remove the water, then sputtered with gold at $20 \mathrm{~mA}$ for $45 \mathrm{~s}$, and examined under SEM (FEI 430 Nova NanoSEM, USA). In addition, compression test was performed on cylindrical hydrogels with $8-\mathrm{mm}$ diameter and 5-mm heigth to determine the mechanical strength of 1,3 and 6\% HA-Tyr hydrogels. The analysis was performed at $2-\mathrm{mm} / \mathrm{min}$ loading rate and under a load of $5 \mathrm{~N}$ (Cellscale, Canada). Young's moduli were calculated based on the stress/strain curves. All the measurements were performed in duplicate.

\subsection{CExo release study from HA-Tyr/CExo gels}

To assess the potential of the HA-Tyr/CExo as a cell induction scaffold, CExo release kinetics was investigated. For this purpose, HA-Tyr/CExo hydrogels containing 1-mg CExo were prepared and incubated in cell culture media in an incubator at $37^{\circ} \mathrm{C}$ for different time points $(30 \mathrm{~min}$, $1 \mathrm{~h}, 3 \mathrm{~h}, 6 \mathrm{~h}, 1 \mathrm{~d}, 3 \mathrm{~d}$ ). BCA assay was applied to the $100 \mu \mathrm{L}$ of supernatant of each gel to measure exosomal protein content after each time point. Each time point was studied triplicate.

\subsection{Investigation of cell viability utilizing the Live-Dead assay and MTS test}

Suitability of HA-Tyr/CExo for cell culture applications and effects of different parameters such as gel mechanical property and CExo concentration on cell survival and proliferation were investigated with calcein/ethidium homodimer-1 (ethd-1) staining and MTS (3-(4,5-dimethylthiazol-2-yl)-5-(3-carboxymethoxyphenyl)-2-(4-sulfophenyl)-2H-tetrazolium) testing. For a live-dead assay, hMSCs (5000 cells/gel) were seeded in HA-Tyr/CExo and on tissue culture plastic (TCP, positive control), cultured for 1 and 7 days, and stained with calcein $(4 \mu \mathrm{M})$ and ethd- $1(2 \mu \mathrm{M})$ (Molecular Probes, Thermo Fisher, UK) in the dark for $30 \mathrm{~min}$ at $37^{\circ} \mathrm{C}$. The cells were monitored under fluorescence microscope (Leica DMIL, Germany) at 488 and 527$\mathrm{nm}$ excitation wavelengths for calcein and ethd-1, respectively.

Cell proliferation was also tested using the MTS kit (Cell Titre, Promega, USA), unlikely the cell density of 7500 cells/hydrogel in this case. After definite time points $(1,3$, and 7 days), the waste medium was discarded, and $20 \mu \mathrm{L}$ of MTS reagent was added in each well containing $100 \mu \mathrm{L}$ of fresh culture medium. After $1 \mathrm{~h}$ incubation in the dark at $37^{\circ} \mathrm{C}$, absorbance values for HA-Tyr $(1,3,6 \%)$, HA-Tyr/ CExo, that comprise varying concentrations of exosomes $(10,50,100 \mu \mathrm{g})$, and TCP (positive control) groups were recorded at $490 \mathrm{~nm}$. Each parameter was studied triplicate. Tukey's multiple comparison test was used for the statistical evolution and comparison of groups including hydrogels in different concentrations, and hydrogels with different CExo concentrations.

\subsection{Investigation of cardiac gene expressions}

Cardiac gene expressions by hMSCs that were cultured within HA-Tyr and HA-Tyr/CExo hydrogels were investigated with RT-qPCR. To this end, total RNA was extracted from hydrogels using a total RNA isolation kit (GeneDireX, USA), quantified with a spectrophotometer (Thermo Scientific, Multiskan Sky Microplate Spectrophotometer), and a total of 120 ng RNA was reverse-transcribed using iScript cDNA Synthesis Kit (Bio-Rad, USA). For RT-qPCR, each reaction was set duplicate, using SYBR green mastermix and performed in a Bio-Rad CFX96 instrument. Results were normalized to the reference gene (GAPDH), and the statistical differences in gene expressions were evaluated using a two-way analysis of variance test. Primer sequences used in this study were listed in Table S1.

\section{Results}

\subsection{Characterisation of CExo}

In order to characterize exosomes isolated with ultracentrifugation method, three different characterization techniques namely TEM, ELISA test and BCA test were applied. TEM micrograph confirmed that isolated vesicles were in spherical morphology, having a size around $50 \mathrm{~nm}$ (Fig. S2a). Besides, the number of CD63+ exosome particles was found to be $1.17 \times 10^{10}$ (optic density: 0.62; calibration graph has been presented in Fig. S2b), which further proved the success of exosome isolation. Exosome 


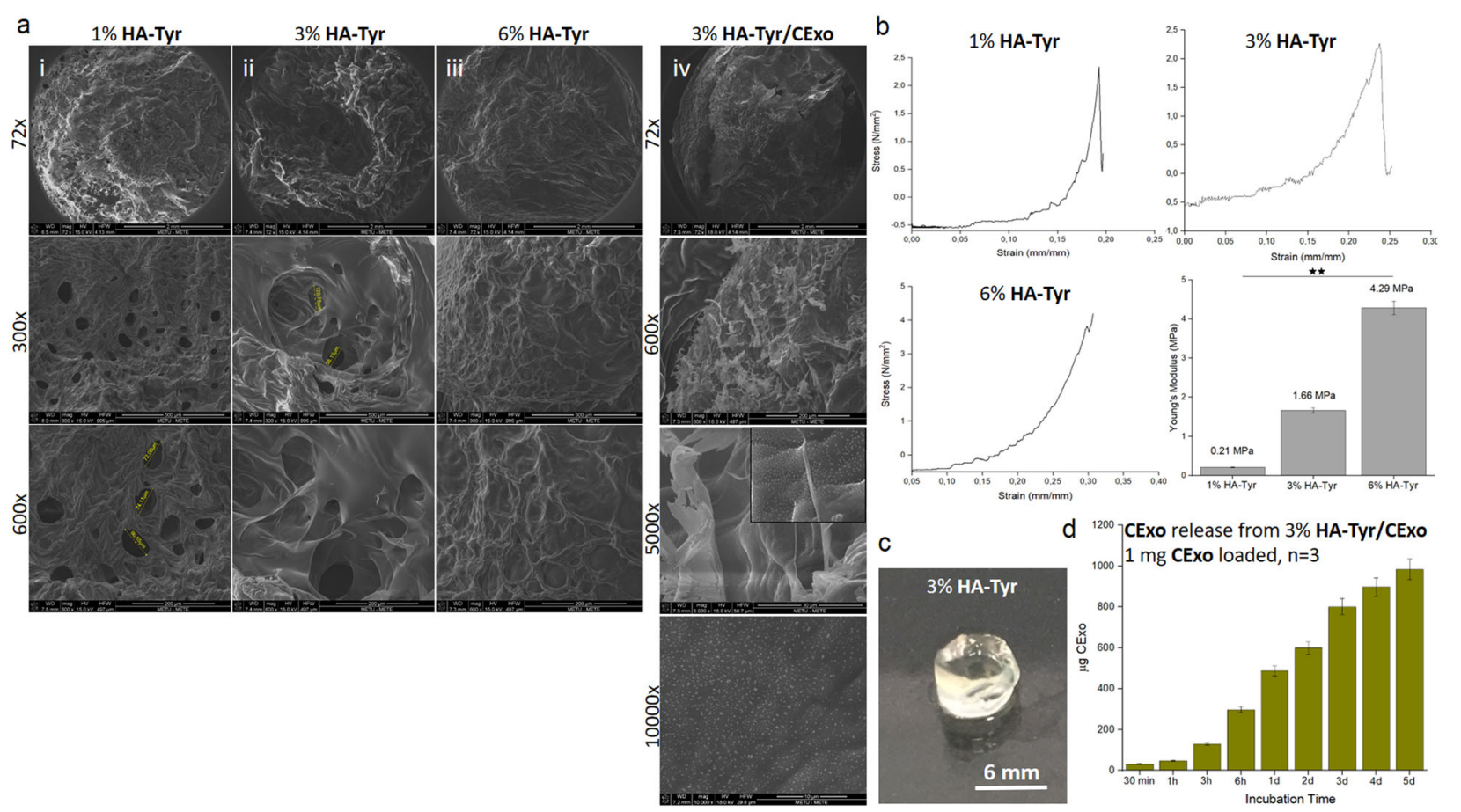

Fig. 1 Characterization of HA-Tyr and HA-Tyr/CExo hybrid hydrogels: microstructural characterization-using SEM-of HA-Tyr hydrogels in different stiffness as well as HA-Tyr/CExo hybrid hydrogel (a). Stress-strain curves related to compression test of 1,3

concentration was calculated using the BCA test in terms of total protein content of CExo. Utilizing the calibration equation (presented in Fig. S3) and using the absorbance obtained by CExo (optic density: 1.52), CExo concentration was found to be $3.7 \mathrm{mg} \mathrm{mL}^{-1}$.

\subsection{Micro-scale investigation and mechanical properties of HA-Tyr and HA-Tyr/CExo hydrogels}

SEM observations revealed that the HA-Tyr hydrogels exhibited a whole and microporous morphology (Fig. 1a (i-iii)), as previously demonstrated [34]. In addition, average pore sizes for each gel were calculated using imageJ software (National Institute of Health) considering ten pores per SEM image (three SEM images were used for each gel concentration) and found to be $75.57 \pm 5.20,69.20 \pm 4.80$ and $<50 \mu \mathrm{m}$ for 1,3 and $6 \%$ HA-Tyr, respectively. Expectedly, it was observed that the pore diameter decreased slightly with increasing gel concentration. In the HA-Tyr/CExo hydrogel, the exosomes were seen to integrated with HA-Tyr and were evenly and individually distributed throughout the gel (Fig. 1a (iv)).

The main goal of this design was to develop a bioactive and robust hydrogel that could trigger a particular process. To assess the mechanical stability of the hydrogels, which is essential to reveal the gel response and failure, compression test was applied in 1, 3 and 6\% HA-Tyr. The compressive and 6\% HA-Tyr (b). Macro-view and 3D-view of HA-Tyr-based hydrogels (c). CExo release kinetics from 3\% HA-Tyr/CExo hydrogels (d) $(* * p<0.01)$

moduli of HA-Tyr hydrogels with different concentrations (1, 3 and 6\%) were obtained from the linear region of typical stress-strain curves (Fig. 1b). The Young's moduli of 1,3 , and $6 \%$ HA-Tyr $(n=2)$ were found to be $0.21,1.66$ and $4.29 \mathrm{MPa}$, respectively, which were seen to increase with ascending HA-Tyr concentration. In addition, HA-Tyrbased gels were seen to have transparency (Fig. 1c), that is important in cell culture applications-particularly in microscopic observations.

\subsection{HA-Tyr-based gels release CExo in a timely manner}

Optimal release kinetics is a crucial parameter for efficient induction of the encapsulated cells as well as promoting the repair of damaged issue. Therefore, it was tested whether HA-Tyr/CExo hydrogel could effectively retain exosomes inside or it released immediately after being treated with the medium. HA-Tyr/CExo hydrogel retained almost half of the CExo within the gel in the first 2 days, while the cumulative release of CExo was found until nearly 5 days (Fig. 1d).

\section{4 hMSCs survive and proliferate in 3D HA-Tyr and HA-Tyr/CExo hybrid hydrogels}

To investigate the pertinence of the material as a cell culture construct, live/dead imaging with calcein and ethd-1 in 


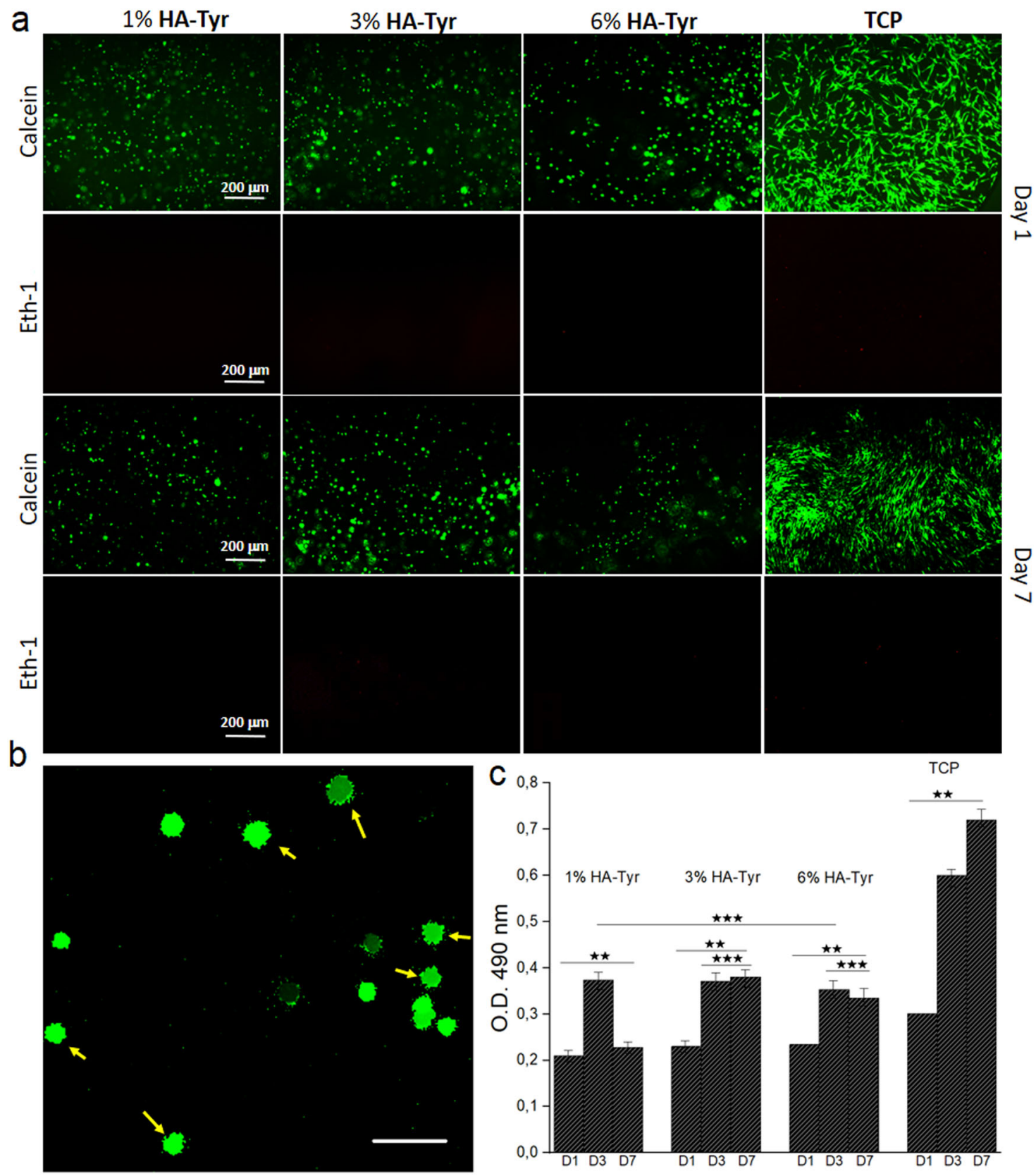

Fig. 2 Cell viability and proliferation study: fluorescence images obtained with calcein and Ethd-1 for hMSCs cultured within HA-Tyr hydrogels with different stiffness (a). Confocal image of hMSCs

within 3\% HA-Tyr showing the slight cell attachment and spreading. Scale bar $50 \mu \mathrm{m}(\mathbf{b})$. MTS testing results for hMSCs cultured within 1, 3 and $6 \%$ HA-Tyr for 1,3 and 7 days (c) $(* * p<0.01, * * * p>0.05)$

order to monitor the viability of the cells in addition to MTS tests were applied. As expected, HA-Tyr did show good cytocompatibility regardless of concentrations (Fig. 2a). However, 3\% HA-Tyr did show better cell survival after 7 days, with a significantly higher number of viable cells compared to 1 and 6\% HA-Tyr. This might be attributed to the optimal mechanical sensing by the cells for them to slightly attach to the HA-Tyr (Fig. 2b), which is also an important process for cell differentiation. On the other hand, almost no dead cells were observed. To further examine the potential of the hydrogels for cell proliferation, MTS test was conducted for 1, 3 and 6\% HA-Tyr. Cell numbers were increased from day 1 to 7 within 3\% HA-Tyr, remained stable after day 3 within 6\% HA-Tyr, while it decreased after day 3 within $1 \%$ HA-Tyr (Fig. 2c).

In order to reveal the effects of CExo on cell viability and proliferation, these experiments were repeated for 1 , 3 and 6\% HA-Tyr/CExo hydrogels that bear 50- $\mu \mathrm{g}$ CExo. Fluorescence images obtained with calcein and ethd-1 staining showed no toxicity-dead cells—and 


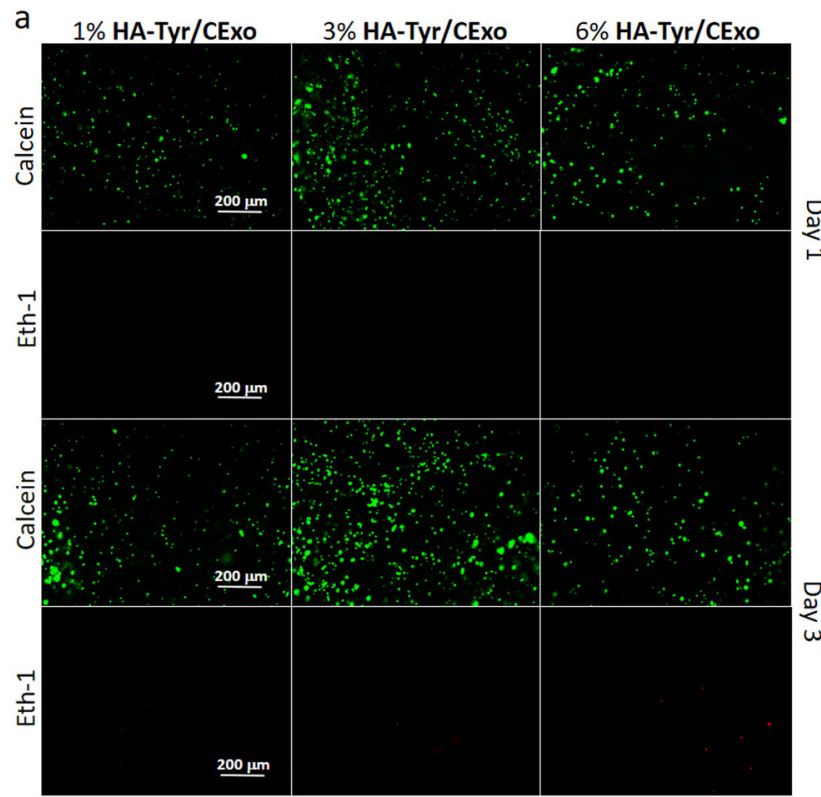

Fig. 3 Cell viability and proliferation study for hybrid hydrogels: fluorescence images obtained with calcein and Ethd-1 for hMSCs cultured within HA-Tyr/CExo hydrogels with different stiffness (a).

good viability at days 1 and 3 (Fig. 3a). Amongst the gels, 3\% HA-Tyr/CExo came to the forefront with slightly higher cell viability. MTS results confirmed these observations with a similar fashion in HA-Tyr only hydrogels (Fig. 3b). Therefore, 3\% HA-Tyr/CExo was used throughout the work.

Possible toxic effects of CExo on hMSCs were assessed by treating the cells with varying levels of exosomes. For this purpose, hMSCs were cultured within $3 \%$ HA-Tyr/CExo hydrogels that contain 10, 50 and 100$\mu \mathrm{g}$ CExo. Live/dead assay revealed a similar cell viability image for all the gels with a little difference in favour of 3\% HA-Tyr/CExo loaded with 50- $\mu$ g CExo (Fig. 4a). Unlikely HA-Tyr-only gels, there seemed some dead cells in HA-Tyr/CExo hydrogels, which was minimum in 3\% HA-Tyr/CExo loaded with 50- $\mu$ g CExo. MTS testing further supported live/dead assay results and indicated an insignificant difference between groups (Fig. 4b).

\subsection{CExo differentiate hMSCs into early cardiac progenitor cells and induce cardiac gene expressions}

The goal of this study was to design robust, biocompatible and bioactive hydrogel that is able to induce hMSCs toward a cardiogenic lineage benefiting from natural inducers instead of chemicals or growth factors. To prove the hypothesis (Fig. S1b), hMSCs were exposed to CExo within 3\% HA-Tyr/CExo (10, 50 and $100 \mu \mathrm{g})$ hydrogels for 3 and 10 days, and expressions of cardiac $b$

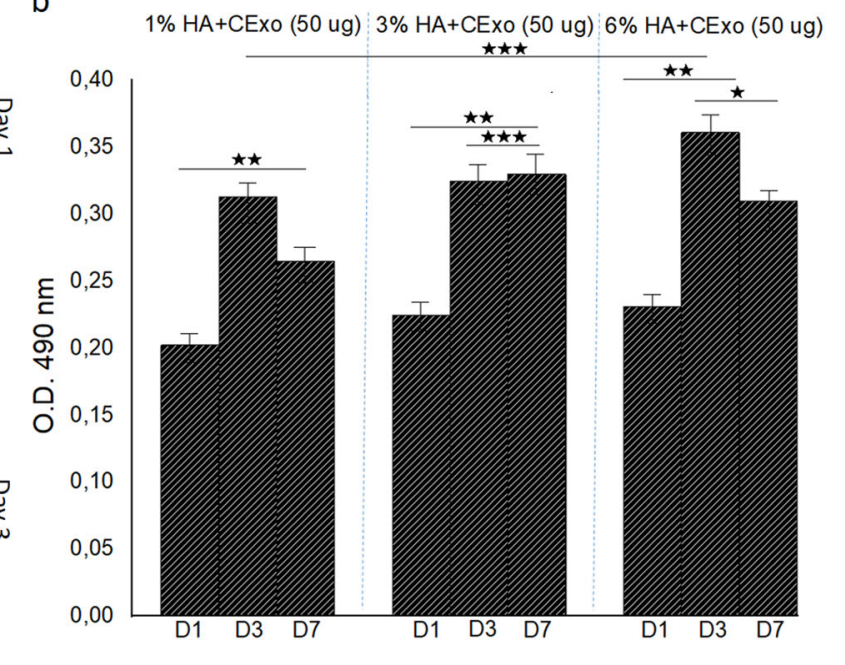

MTS testing results for hMSCs cultured within 1, 3 and 6\% HA-Tyr/ CExo $(50 \mu \mathrm{g})$ for 1,3 and 7 days (b) $(* p<0.05, * * p<0.01$, $* * * p>0.05)$

genes-GATA4, T-box transcription factor (Tbx5), Nkx2.5 and cardiac troponin $\mathrm{T}$ (cTnT) - were investigated by RT-qPCR. The cells cultured in 3\% HA-Tyr/ CExo hydrogels were seen to begin expressing early cardiac progenitor markers, GATA4, Tbx5, Nkx2.5, after 3 days' induction (Fig. 5). These expressions significantly increased at day 10 , which were almost doubled compared to day 3 . The cells cultured within $3 \%$ HA-Tyr and on TCP did not exhibit this behaviour. On the other hand, the expression of cTnT by the cells inoculated in HA-Tyr/CExo hydrogels was not significant. Though the expression of cTnT by the cells within 3\% HA-Tyr/CExo $(100 \mu \mathrm{g})$ was nearly four times higher at day 10 compared to day 3 , the cumulative expression of these gene was below twofolds compared to cells cultured within 3\% HA-Tyr and on TCP (negative controls in this case).

\section{Discussion}

In this study, it was intended to harness the biological potential of tissue-specific cells-derived exosomes for the induction of hMSCs into cardiac-like cells. For this, 3D cell culture construct consisting of HA-Tyr as scaffolding material and CExo as biological elements was developed.

HA-Tyr/CExo hydrogel was thoroughly characterized with SEM, micro-mechanical analysis, and by examining exosome-release kinetics. In addition, live/dead assay and MTS testing were applied so as to reveal the potential for 


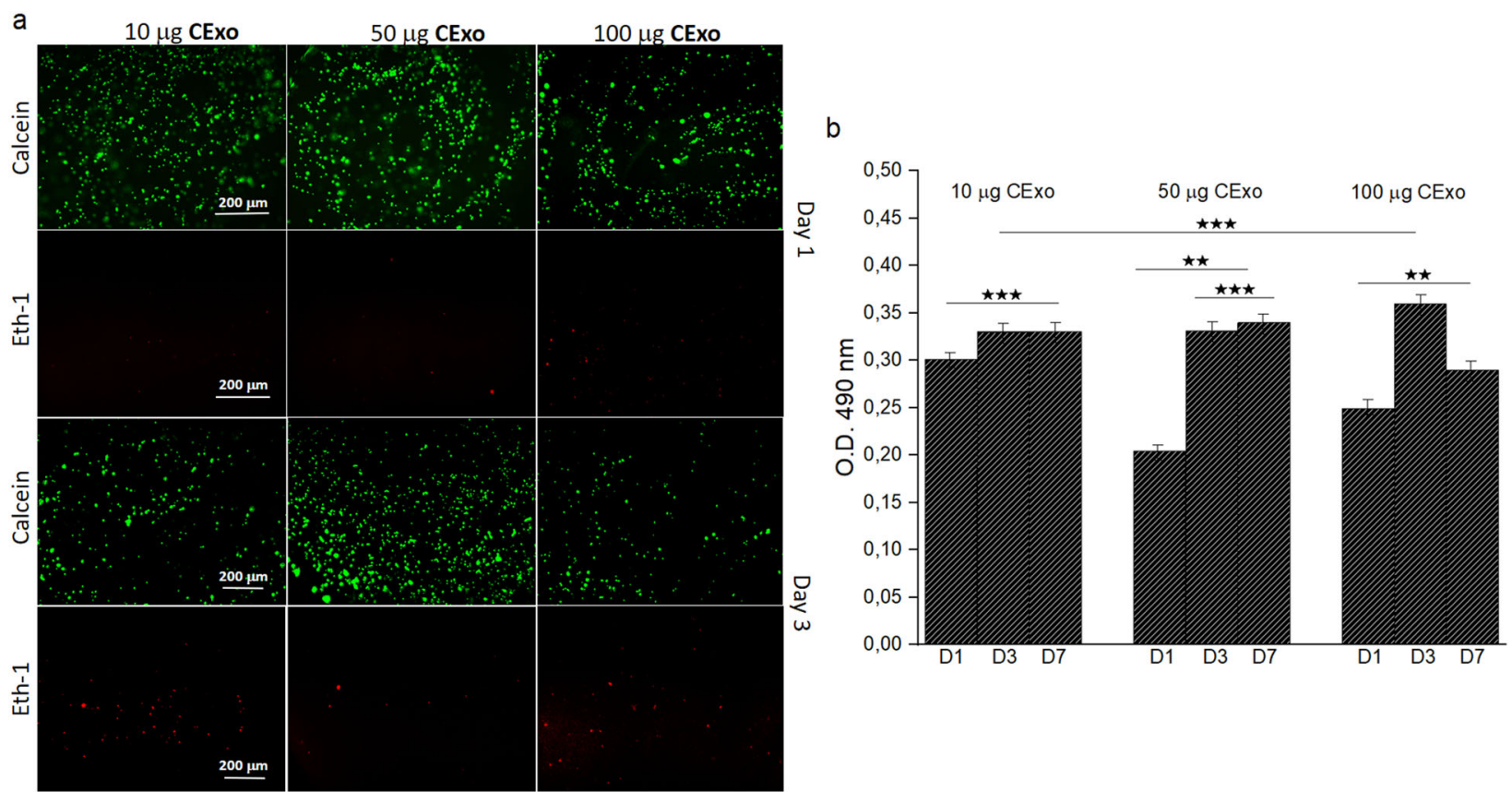

Fig. 4 Investigation of effects of CExo on cell viability and proliferation: live-dead assay images of hMSCs cultured within 3\% HATyr/CExo hydrogels that contain varying concentrations of CExo (10,

cell growth and proliferation. SEM observation suggested that exosomes were successfully encapsulated inside the hydrogel, and covered the pores and flakes such that they combined and retained all the features of HA-Tyr and exosomes (Fig. 1a). The obtained hydrogels were extremely strong and tough-as well as transparent-(Fig. 1b, c), of which mechanical strength can be tuned by adjusting the concentration. The obtained release profile further demonstrated that exosomes were effectively encapsulated in the hydrogel, and exhibited a sustained release behaviour (Fig. 1d). This property is essential for cell induction in vitro/vivo by durably exerting the potential of exosomes and is expected to implement defect regeneration when applied in vivo. Similar release kinetics of exosomes were reported previously [35, 36].

Live/dead assay and MTS testing revealed that 3\% HATyr was a suitable candidate for hMSCs survival (Fig. 2). A decrease in cell number within 1\% HA-Tyr after day 3 could be explained with the poor mechanical strength of the material, which resulted in cell leakage. Considering the live/dead assay and MTS testing results, it can be concluded that HA-Tyr concentration does not affect cell viability/ proliferation in the short term, but it does at the long-term culture. In addition, HA-Tyr hydrogels are nontoxic and provide a suitable environment for cell culture applications. Considering the better cell viability and proliferation, in addition to moderate mechanical strength, which is important for the target application-soft tissue-[37, 38], 3\% HA-Tyr/CExo was selected and used throughout the work.
50 and $100 \mu \mathrm{g}$ ) (a). MTS testing results for hMSCs cultured within 3\% HA-Tyr/CExo $(10,50$ and $100 \mu \mathrm{g})$ for 1,3 and 7 days $(\mathbf{b})(* * p<0.01$, $* * * p>0.05)$

In addition, the live/dead assay and MTS testing showed that CExo had no toxic effects on hMSCs regardless of the concentration (Figs 3 and 4). These findings were in accordance with literature works [39, 40], and demonstrated that exosomes can be safely used in biological applications.

Cardiac-cell-derived exosomes were shown to increase cardiac-related gene (Nkx2.5, GATA4 and Tbx5) expressions in hMSCs (Fig. 5). However, the increase in cTnT was not significant. This low-level expression of cTnT compared to other cardiac genes was indeed meaningful in as much as this gene is expressed in a mature form of cardiac cells - cardiomyocytes - that come out in the later stages of cardiogenesis [41, 42]. Similar findings have previously been reported [43]. Another striking finding in gene expression study was that 3\% HA-Tyr/CExo hydrogels induced cardiac gene expressions in hMSCs in a dosedependent manner (Fig. 5). Expressions in GATA4 and Tbx5 increased with ascending exosome levels, from 10 to $100 \mu \mathrm{g}$. That is, cardiac gene expressions can be tuned by changing CExo concentration.

\section{Conclusion}

In this proof-of-the-concept study, exosomes derived from cardiac cells were combined with HA-based hydrogels, of which cardiogenic induction potential was then tested. This strategy harnessing the biological potentials of exosomes could be effectively utilized in inducing cardiac gene 

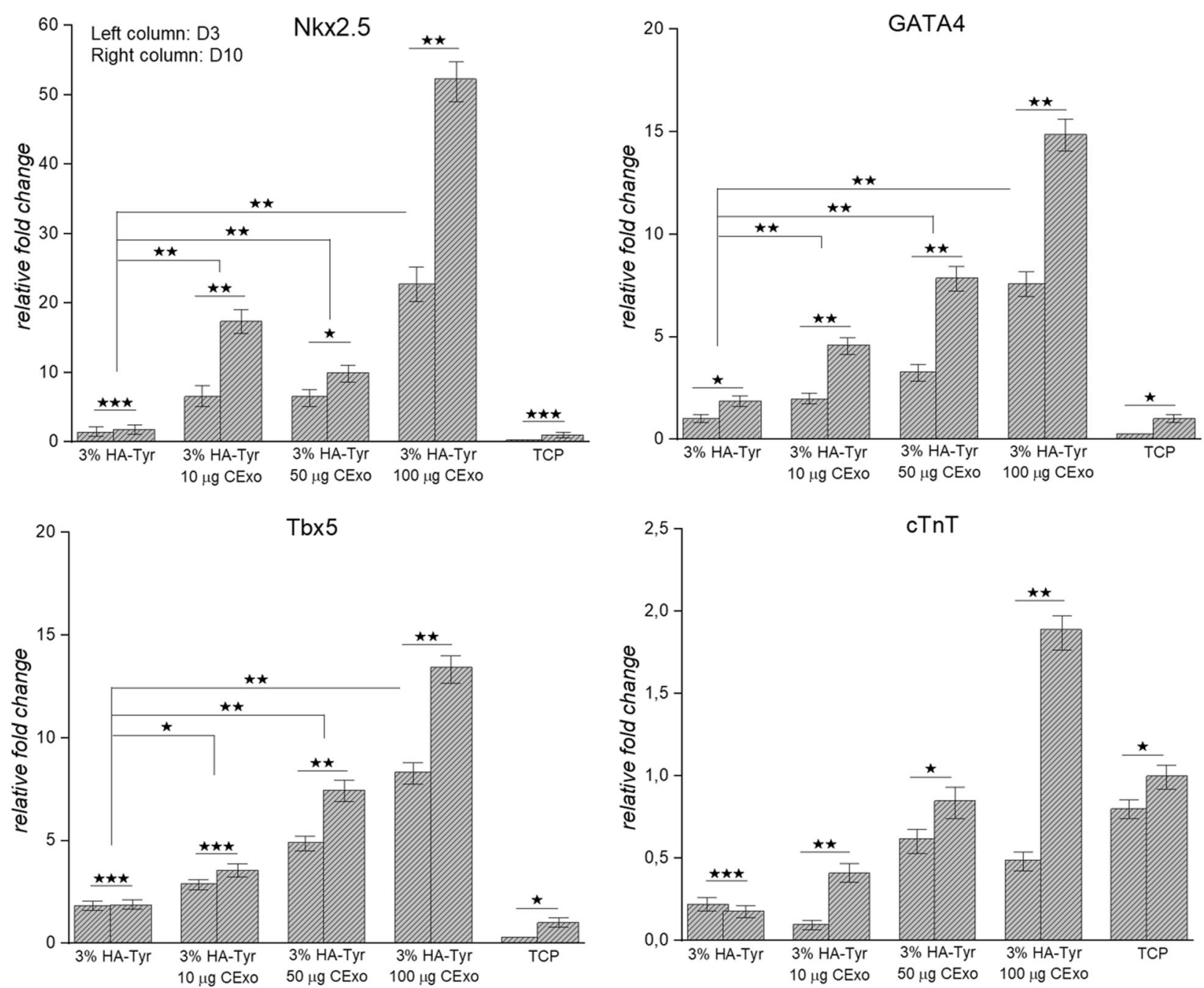

Fig. 5 Gene expression study: expressions of cardiac genes (Nkx2, GATA4, Tbx5, cTnT) in 3\% HA-Tyr/CExo (10, 50 and $100 \mu \mathrm{g})$ hydrogels after 3 (left column) and 10 (right column) days of induction $(* p<0.05, * * p 0.01, * * * p>0.05)$

expressions in hMSCs; however, it did not ensure a full differentiation of the cells into functional cardiomyocytes. Instead, it is extrapolated and assumed that GATA4 $+/ \mathrm{Nkx} 2.5+/ \mathrm{Tbx} 5+/ \mathrm{cTnT}$-early cardiac progenitors were formed. These findings will be validated further in the future using histological techniques as well as mechanistic approaches such as transcript profiling and proteomics. This strategy is anticipated to have an enormous effect on the regeneration of damaged tissues in the coming years.

Acknowledgements The author thanks Dr. Yavuz Emre Arslan for donating hMSCs, Dr. Sedat Odabas (Ankara University, Turkey) for his helps in SEM imaging and mechanical testing and Ece Karakaya for her contribution to the exosome isolation study.

\section{Compliance with ethical standards}

Conflict of interest The author declares that he has no conflict of interest.
Publisher's note Springer Nature remains neutral with regard to jurisdictional claims in published maps and institutional affiliations.

Open Access This article is licensed under a Creative Commons Attribution 4.0 International License, which permits use, sharing, adaptation, distribution and reproduction in any medium or format, as long as you give appropriate credit to the original author(s) and the source, provide a link to the Creative Commons license, and indicate if changes were made. The images or other third party material in this article are included in the article's Creative Commons license, unless indicated otherwise in a credit line to the material. If material is not included in the article's Creative Commons license and your intended use is not permitted by statutory regulation or exceeds the permitted use, you will need to obtain permission directly from the copyright holder. To view a copy of this license, visit http://creativecommons. org/licenses/by/4.0/.

\section{References}

1. Armiñán A, Gandía C, Bartual M, García-Verdugo JM, Lledó E, Irabet $\mathrm{V}$, et al. Cardiac differentiation is driven by NKX2.5 and 
GATA4 nuclear translocation in tissue-specific mesenchymal stem cells. Stem Cell Dev. 2009;18:907-18.

2. Behrens AN, Iacovino M, Lohr JL, Ren Y, Zierold C, Harvey RP, et al. Nkx2-5 mediates differential cardiac differentiation through interaction with Hoxa10. Stem Cell Dev. 2013;22:2211-20.

3. Cai B, Li J, Wang J, Luo X, Ai J, Liu Y, et al. microRNA-124 regulates cardiomyocyte differentiation of bone marrow-derived mesenchymal stem cells via targeting STAT3 signaling. Stem Cells. 2012;30:1746-55.

4. Guo X, Bai Y, Zhang L, Zhang B, Zagidullin N, Carvalho K, et al. Cardiomyocyte differentiation of mesenchymal stem cells from bone marrow: new regulators and its implications. Stem Cell Res Ther. 2018;9:44.

5. Antonitsis P, Ioannidou-Papagiannaki E, Kaidoglou A, Papakonstantinou C. In vitro cardiomyogenic differentiation of adult human bone marrow mesenchymal stem cells. The role of 5azacytidine. Interact Cardiovasc Thorac Surg. 2007;6:593-7.

6. Choi SC, Yoon J, Shim WJ, Ro YM, Lim D-S. 5-azacytidine induces cardiac differentiation of P19 embryonic stem cells. Exp Mol Med. 2014;36:515-23.

7. Cavaliere A, Bufalari A, Vitali R. 5-Azacytidine carcinogenesis in BALB/c mice. Cancer Lett. 1987;37:51-8.

8. Zhao XL, Yang B, Ma LN, Dong YH. MicroRNA-1 effectively induces differentiation of myocardial cells from mouse bone marrow mesenchymal stem cells. Artif Cells Nanomed Biotechnol. 2016;44:1665-70.

9. Chen X, Soibam B, Benham A, Xu X, Chopra M, Peng X, et al. miR-322/-503 cluster is expressed in the earliest cardiac progenitor cells and drives cardiomyocyte specification. PNAS. 2016;113:9551-6.

10. Garate X, Greca A, Neiman G, Blüguermann C, Velazque NLS, Moro LN, et al. Identification of the miRNAome of early mesoderm progenitor cells and cardiomyocytes derived from human pluripotent stem cells. Sci Rep. 2018;8:8072.

11. Khajeniazi S, Solati M, Yazdani Y, Soleimani M, Kianmehr A. Synergistic induction of cardiomyocyte differentiation from human bone marrow mesenchymal stem cells by interleukin 1beta and 5-azacytidine. Biol Chem. 2016;397:1355-64.

12. Gwak SJ, Bhang SH, Yang HS, Kim SS, Lee DH, Lee SH, et al. In vitro cardiomyogenic differentiation of adipose-derived stromal cells using transforming growth factor-beta1. Cell Biochem Funct. 2009;27:148-54

13. Zhang GW, Gu TX, Guan XY, Sun XJ, Qi X, Li XY, et al. HGF and IGF-1 promote protective effects of allogeneic BMSC transplantation in rabbit model of acute myocardial infarction. Cell Proliferat. 2015;48:661-70.

14. Yi Q, Xu H, Yang K, Wang Y, Tan B, Tian J, et al. Islet-1 induces the differentiation of mesenchymal stem cells into cardiomyocytelike cells through the regulation of Gen5 and DNMT-1. Mol Med Rep. 2017;15:2511-20.

15. Willems E, Bushway PJ, Mercola M. Natural and synthetic regulators of embryonic stem cell cardiogenesis. Pediatr Cardiol. 2009;30:635-42.

16. Derkus B, Emregul KC, Emregul E. A new approach in stem cell research-exosomes: their mechanism of action via cellular pathways. Cell Biol Int. 2017;41:466-75.

17. Lamichhane TN, Sokic S, Schardt JS, Raiker RS, Lin JW, Jay SM. Emerging roles for extracellular vesicles in tissue engineering and regenerative medicine. Tissue Eng Part B. 2015;21:45-54.

18. Choi H, Kim Y, Mirzaaghasi A, Heo J, Kim YN, Shin JH, et al. Exosome-based delivery of super-repressor I $\mathrm{B} \alpha$ relieves sepsisassociated organ damage and mortality. Sci Adv. 2020;6:6980.

19. Eylem CC, Yilmaz M, Derkus B, Camci CB, Nemutlu E, Yilmaz $\mathrm{E}$, et al. Untargeted multi-omic analysis of colorectal cancerspecific exosomes reveals joint pathways of colorectal cancer in both clinical samples and cell culture. Cancer Lett. 2020;469:186-94.

20. Anderson MR, Pleet ML, Enose-Akahata Y, Erickson J, Monaco MC, Akpamagbo Y, et al. Viral antigens detectable in CSF exosomes from patients with retrovirus associated neurologic disease: functional role of exosomes. Clin Transl Med. 2018;7:24.

21. Yuan Q, Li X, Zhang S, Wang H, Wang Y. Extracellular vesicles in neurodegenerative diseases: insights and new perspectives. Genes Dis. https://doi.org/10.1016/j.gendis.2019.12.001.

22. Takeda YS, Xu Q. Neuronal differentiation of human mesenchymal stem cells using exosomes derived from differentiating neuronal cells. PLoS ONE. 2015;10:e0135111.

23. Jung YJ, Kim HK, Cho Y, Choi JS, Woo CH, Lee KS, et al. Cell reprogramming using extracellular vesicles from differentiating stem cells into white/beige adipocytes. Sci Adv. 2020;6:6721.

24. Narayanan K, Kumar S, Padmanabhan P, Gulyas B, Wan ACA, Rajendran VM. Lineage-specific exosomes could override extracellular matrix mediated human mesenchymal stem cell differentiation. Biomaterials. 2018;182:312-22.

25. Huang C-C, Narayanan R, Alapati S, Ravindran S. Exosomes as biomimetic tools for stem cell differentiation: Applications in dental pulp tissue regeneration. Biomaterials. 2016;111:103-15.

26. Forterre A, Jalabert A, Chikh K, Pesenti S, Euthine V, Granjon A, et al. Myotube-derived exosomal miRNAs downregulate Sirtuin1 in myoblasts during muscle cell differentiation. Cell Cycle. 2014;13:78-89.

27. Li X, Yang Z, Ni W, Jiang J, Li S, Li Z, et al. Exosomes derived from cardiac progenitor cells attenuate CVB3-induced apoptosis via abrogating the proliferation of CVB3 and modulating the mTOR dignaling pathways. Cell Death Dis. 2019;10:691.

28. Barile L, Lionetti V, Cervio E, Matteucci M, Gherghiceanu M, Popescu LM, et al. Extracellular vesicles from human cardiac progenitor cells inhibit cardiomyocyte apoptosis and improve cardiac function after myocardial infarction. Cardiovasc Res. 2014;103:530-41.

29. Loyer X, Zlatanova I, Devue C, Yin M, Howangyin KY, Klaihmon $\mathrm{P}$, et al. Intra-cardiac release of extracellular vesicles shapes inflammation following myocardial infarction. Circ Res. 2018;123:100-6.

30. Cai B, Li J, Wang J, Luo X, Ai J, Liu Y, et al. microRNA-124 regulates cardiomyocyte differentiation of bone marrow-derived mesenchymal stem cells via targeting STAT3 signalling. Stem Cells. 2012;30:1746-55.

31. Derkus B, Okesola BO, Barrett DW, D'Este M, Chowdhury TT, Eglin D, et al. Multicomponent hydrogels for the formation of vascularized bone-like constructs in vitro. Acta Biomater. 2020;109:82-94.

32. Rienks M, Papageorgiou A, Frangogiannis NG, Heymans S. Myocardial extracellular matrix. Circ Res. 2014;114:872-88.

33. Bonafè F, Govoni M, Giordano E, Caldarera CM, Guarnieri C, Muscari C. Hyaluronan and cardiac regeneration. J Biomed Sci. 2014;21:100.

34. Xu K, Narayanan K, Lee F, Bae KH, Gao S, Kurisawa M. Enzyme-mediated hyaluronic acid-tyramine hydrogels for the propagation of human embryonic stem cells in 3D. Acta Biomater. $2015 ; 24: 159-71$

35. Zhang K, Zhao X, Chen X, Wei Y, Du W, Wang Y, et al. Enhanced therapeutic effects of MSC-derived exosomes with an injectable hydrogel for hindlimb ischemia treatment. ACS Appl Mater Interfaces. 2018;10:30081-91.

36. Shafei S, Khanmohammadi M, Heidari R, Ghanbari H, Nooshabadi VT, Farzamfar S, et al. Exosome loaded alginate hydrogel promotes tissue regeneration in full-thickness skin wounds: an in vivo study. J Biomed Mater Res. 2020;108:545-56. 
37. Guimarães CF, Gasperini L, Marques AP, Reis RL. The stiffness of living tissues and its implications for tissue engineering. Nat Rev Mater. 2020;5:351-70.

38. Huyer LD, Montgomery M, Zhao Y, Xiao Y, Conant G, Korolj A, et al. Biomaterial based cardiac tissue engineering and its applications. Biomed Mater. 2015;10:034004.

39. Ha DH, Kim S-D, Lee J, Kwon H, Park G-H, Yang SH, et al. Toxicological evaluation of exosomes derived from human adipose tissue-derived mesenchymal stem/stromal cells. Regul Toxicol Pharmacol. 2020;115:104686.

40. Badawi XZM, Pomeroy S, Sutaria DS, Xie Z, Baek A, Jiang J, et al. Comprehensive toxicity and immunogenicity studies reveal minimal effects in mice following sustained dosing of extracellular vesicles derived from HEK293T cells. J Extracell Vesicles. 2017;6:1324730.

41. Aguilar-Sanchez C, Michael M, Pennings S. Cardiac stem cells in the postnatal heart: lessons from development. Stem Cells Int. 2018;2018:1247857.

42. Chan S-K, Li H-J, Hsueh Y-C, Lee DS, Chen J-H, Hwang S-M, et al. Fibroblast growth factor-10 promotes cardiomyocyte differentiation from embryonic and induced pluripotent stem cells. PLoS ONE. 2010;5:e14414.

43. Agarwal P, Zhao S, Bielecki P, Rao W, Choi JK, Zhao Y, et al. One-step microfluidic generation of pre-hatching embryo-like core-shell microcapsules for miniaturized 3D culture of pluripotent stem cells. Lab Chip. 2013;13:4525. 